\title{
Teste empírico de um modelo teórico sobre o estilo da orientação cultural e condutas desviantes em jovens de diferentes contextos socioescolares
}

\author{
Empirical testing of a theoretical model about the style of cultural orientation and deviant \\ conduct of young people in different social and school contexts
}

Nilton Soares Formiga

\section{Resumo}

Mestre em Psicologia Social pela Universidade Federal da Paraíba (UFPB), Doutorando na mesma universidade, João Pessoa, PB - Brasil, e-mail: nsformiga@yahoo.com

Recebido: $14 / 12 / 2010$ Received: $12 / 14 / 2010$

Aprovado: $18 / 05 / 2011$ Approved: 05/18/2011

\begin{abstract}
Estudos já realizados defenderam que a orientação cultural social se relaciona positivamente com a conduta desviante. Por outro lado, a orientação individual tem relação positiva com tais condutas. Neste estudo, pretende-se testar um modelo teórico entre estilo de orientação cultural e conduta desviante de jovens em diferentes contextos socioescolares, proposta sugerida, mas ainda não efetivada. Duas amostras de jovens entre 14 a 21 anos, do sexo masculino e do sexo feminino, responderam as escalas dos atributos de individualismo e coletivismo e das condutas desviantes. No programa AMOS GRAFICS 18.0, comprovou-se que, independente do contexto sócio-escolar, as orientações individualistas explicaram, positivamente, as condutas desviantes; e as orientações coletivistas explicaram negativamente tais condutas.
\end{abstract}

Palavras-chave: Jovens. Contexto escolar. Orientação cultural. Condutas desviantes. Modelo causal.

\begin{abstract}
Existing studies have argued that the socio-cultural orientation is positively related to deviant behavior, on the other hand, individual orientation has a positive relation with such conducts. This study aims to test a theoretical model about the style of cultural orientation of deviant behavior in young people in different social and school environments. Such proposal was suggested, but not yet fulfilled. Two groups of youths, ranging between 14 and 21 years old, both male and female, were sampled and answered the scale of the attributes of individualism and collectivism and deviant conduct. In the AMOS GRAFICS 18.0 computer program it was shown that, regardless of social and school context, the individualistic orientations explained the deviant behaviors in a positive way; and collectivist orientations explained the same behaviors negatively.
\end{abstract}

Keywords: Youths. School context. Cultural orientation. Deviant behavior. Causal model. 


\section{Introduç̃̃o}

A literatura sobre o desenvolvimento e história da civilização humana percorre uma dinâmica dicotômica em relação à orientação individualidade-coletividade, tradição-modernidade, natural-adquirido quando se refere ao estabelecimento de um padrão de conduta. Geralmente, tende-se a priorizar uma ou outra dessas orientações com o objetivo de compreender os processos psicossociais e sua influência na manutenção de um tipo específico de conduta nas relações interpessoais e sociais, principalmente, visando a contribuir para a explicação da conduta desviante entre os jovens na atualidade (Barzun, 2002; Dumont, 1985; Elias, 1994; Fernández-Armesto, 1999).

Não é de hoje que o problema da conduta desviante em jovens, em todo o mundo, tem interessado aos profissionais em diversas áreas científicas, bem como, aos leigos - pais, professores, etc. Discutem-se quais os motivos da variação do comportamento violento entre os jovens (por exemplo, condutas antissociais e delitivas, uso potencial de drogas, comportamento agressivo etc.) a fim de compreender o porquê do aumento dessas condutas na dinâmica cotidiana juvenil. Pois observa-se que, independente da classe social e econômica em que os jovens se encontrem, isso tem sido um problema que exige uma solução urgente (Formiga, 2005a, b).

Considera-se que as condutas desviantes são causadoras de danos leves ou graves e tangenciam as normas sociais. Tomadas como uma condição de fase da adolescência, de pouca importância, antes de acontecer, parece ser dado à condição de risco psicológico e social que estas possam manifestar nas relações juvenis e seu entorno interpessoal. As condutas podem conduzir os jovens desde a formação de gangs, a jogos de diversão violentos, balbúrdias em festas, vandalismo ao alto consumo de álcool e fumo de drogas ilícitas (Formiga, 2003; Formiga \& Gouveia, 2005; Urra, 2003). Esse fenômeno, na Psicologia, é geralmente explicado com base nas diferenças individuais, seja em direção da estrutura ou traços de personalidade (Romero, Sobral, Luengo \& Marzoa, 2001; Vermeiren, De Clippele \& Deboutte, 2000). Porém ao acompanhar os noticiários sobre os jovens que apresentaram conduta de desvio, não tem sido suficiente o poder preditivo dessa variável na organização do quebra-cabeça do problema da delinquência entre os jovens, exigindo novas direções explicativas para a compreensão dessa situação social grave.
Acredita-se que o aumento das condutas desviantes, que caracterizam a violência juvenil, na época atual, se deve às mudanças culturais que vêm ocorrendo nos países ocidentais, os quais apreendem um espírito individualista, subordinando os interesses e prioridades pessoais ao invés daqueles do grupo (Lipovetsky, 1986). Os jovens que procuram, excessivamente, a obtenção de prestígio, e que, quando na falta de recursos econômicos ou mesmo de apoio social, na maioria das vezes procuram alcançá-los por meio das condutas que convergem à quebra de normas sociais a fim de atender apenas aos seus prazeres e satisfação (Formiga \& Diniz, 2011). Desta maneira, os comportamentos de risco parecem ser legitimados nas relações interpessoais, por exemplo, a busca de novas experiências, de prazer e emoção, saída da monotonia, etc., convergindo para os comportamentos desviantes (Donohew, Hoyle, Clayton, Skinner, Colon \& Rice, 1999; Formiga, 2002; Formiga, Yepes \& Alves, 2005; Gullone \& Moore, 2000).

Nesse contexto, ao se enfatizar a relação entre essas condutas desviantes e os padrões convencionais da conduta cultural estabelecidos socialmente, baseia-se na orientação cultural adotada por cada pessoa, destacando o papel dos atributos dos valores culturais proposto por Triandis $(1995,1996)$. Esse construto, já considerado por Rokeach (1973, 1979) como de fundamental necessidade na explicação dos comportamentos das pessoas, pode ser capaz de orientar tanto as escolhas quanto as atitudes humanas. É possível perceber que a grande preocupação frente à conduta social juvenil diz respeito à cultura individual, passando a estigmatizá-la como a única 'CULTURA', destacando-a como condição do desenvolvimento sócio-humano, excluindo a complexidade e diversidade humana frente à gestão e formação da conduta socialmente desejável nas relações interpessoais (Formiga, 2004).

É pertinente, então, considerar os padrões de orientação cultural de individualismo e coletivismo, uma vez que, ao se adotar um ou outro, o indivíduo irá se comportar de forma coerente com este. Por um lado, o individualismo expressa uma tendência ao sucesso, a valorizar a própria intimidade e uma necessidade de adequar-se ao contexto social, visando a obter recompensas; por outro, o coletivismo define uma tendência à cooperação e ao cumprimento com relação aos demais; internamente, as pessoas com orientação coletivista mantêm fortes relações entre si, podendo compartilhar os mesmos interesses (Gouveia, Clemente \& Vidal, 1998). 
O individualismo e coletivismo são definidos como síndromes culturais e consistem em compartilhar atitudes, crenças, normas, papéis sociais, definições do eu e valores dos membros de cada cultura organizados de forma coerente sob um tema (Triandis, 1995, 1996). As pessoas que se orientam por um tipo ou outro de orientação cultural, vão se comportar de maneira diferente, seja na forma de se autoperceber ou nos seus relacionamentos interpessoais.

No entanto, deve-se salientar que o individualismo e coletivismo não são necessariamente opostos. Como assinalam Sinha e Tripathi (1994), as pessoas são um pouco de cada um, sendo o contexto ou a situação imediata, que vai definir o estilo mais apropriado de comportamento - o tipo de orientação (Triandis, 1995; Triandis, Chen \& Chan, 1998). Em todo caso, espera-se que, em cada pessoa, predomine uma destas orientações, não se podendo ignorar a possibilidade de coexistência das duas (Schwartz, 1990; Sinhá \& Tripathi, 1994), bem como a relação entre esses atributos.

Triandis (1995), ao recuperar a clássica dimensão de poder proposta por Hofstede (1980), que avaliava as dimensões culturais nas empresas, enfatizando o papel do sujeito ou do grupo na dinâmica das sociedades humanas, identifica dois atributos chave para diferenciar os principais tipos de individualismo e coletivismo: horizontal e vertical. 0 atributo horizontal sugere que as pessoas são similares na maioria dos aspectos, especialmente no status. O conceito vertical põe ênfase em aceitar a desigualdade e privilegiar a hierarquia. Esses atributos se combinam com o individualismo e coletivismo formando quatro tipos de orientação, cada um com uma característica principal que melhor descreve a pessoa que adota cada um destes tipos, a saber: individualismo horizontal $\rightarrow$ ser único; individualismo vertical $\rightarrow$ orientado ao êxito; coletivismo horizontal $\rightarrow$ ser cooperativo; e, coletivismo vertical $\rightarrow$ ser servidor.

Considerar estas variáveis - os atributos de individualismo e coletivismo - permite relacionar uma variedade de fatos e pensamentos nas múltiplas facetas da vida social e política (Inglehart, 1991). Sabendo-se ainda que, quando se deseja explicar comportamentos, deve-se recorrer às atitudes; dessa forma, reconhecer a natureza atitudinal desses construtos pode implicar na explicação de alguns comportamentos sociais, neste caso, a conduta desviante entre os jovens.
Um estudo correlacional, desenvolvido por Formiga e Mota (2009), abordava as variáveis sobre o tipo de orientação cultural e a conduta desviante, sendo uma base crítica para o presente estudo. Estes autores observaram uma relação positiva entre o tipo de orientação individualista (por exemplo, Um ser único, Diferente dos demais; Orientado ao êxito, ao triunfo) e as condutas antissociais e delitivas. Resultado inverso foi encontrado para os tipos de orientação coletivista (por exemplo, Cooperador, que colabora; Cumpridor dos deveres com os demais, servidor e Expressivo, amigável e familiar) e as condutas antissocial e delitiva. Assim, de acordo com os autores, uma maior orientação individualista, provavelmente, será maior a conduta desviante, por outro lado, uma orientação coletivista, será capaz de inibir esse tipo de conduta.

Formiga e Diniz (2011) desenvolveram um estudo com as mesmas variáveis a avaliadas por Formiga e Mota (2009), porém atenderam a uma sofisticação metodológica e estatística e procuraram corroborar o estudo correlacional desses autores a partir da perspectiva de modelagem de equação estrutural. Essa técnica vai além dos dados obtidos, e, lineariedade correlacional, considera-se um modelo teórico fixo que oriente a extração das dimensões latentes apresentando uma indicação para a bondade de ajuste do modelo a que se propõe comprovar. Assim, Formiga e Diniz (2011), buscaram com essa técnica, a estimativa da magnitude dos efeitos estabelecida entre variáveis, as quais estão condicionadas ao fato de o modelo especificado (isto é, o diagrama) estar correto e testar se o modelo é consistente com os dados observados, a partir dos indicadores estatísticos, podendo dizer que resultado, modelo e dados são plausíveis, atendendo não a certeza total do modelo, mas a sua probabilidade sistemática na relação entre as variáveis (Farias \& Santos, 2000).

Desta maneira, Formiga e Diniz (2011), além de corroborar o estudo de Formiga e Mota (2009), observaram um modelo estrutural em que o tipo de orientação coletivista associou-se, negativamente, às condutas antissociais e delitivas. Enquanto a orientação individualista esteve associada, positivamente, com ambas as condutas. Apesar de os resultados observados serem consistentes, existe um limite no estudo desses autores: 1 - eles tomaram as variáveis da conduta desviante como variável individual, considerando a conduta antissocial isolada da conduta 
delitiva. Acredita-se que ambas estariam relacionadas, pois, de acordo com Formiga (2003) e Formiga e Gouveia (2003), uma alta pontuação na conduta antissocial, provavelmente, decorrerá em uma conduta delitiva; 2 - Formiga e Diniz (2011) avaliaram uma única amostra de jovens não os separando de acordo com os diferentes contextos socioescolares. Tais limites levaram ao estabelecimento do objetivo central do estudo em questão.

Tomando como base os estudos de Formiga e Mota (2009) e Formiga e Diniz (2011) no presente trabalho, pretende-se, a partir da análise e modelagem de equação estrutural no programa AMOS 18.0, a comprovação empírica e teórica das hipóteses levantadas pelos autores supracitados, isto é: o tipo de orientação cultural coletivista se associaria negativamente, com as condutas desviantes, enquanto a orientação individualista estaria associada, positivamente, com as condutas desviantes. Além de garantir uma robustez e consistência explicativa entre essas variáveis, busca-se provar, a partir das indicações de estudos sugeridas pelos autores já citados, que não existe diferença nos modelos teóricos ao considerar tipos de escola (por exemplo, uma escola pública e outra privada).

\section{Método}

Amostra

Duas amostras compuseram o estudo: uma com 350 jovens de 14 a 19 anos, do sexo masculino e do sexo feminino, da rede de educação particular da cidade de João Pessoa, PB; outra amostra foi composta por 320 jovens de 15 a 19 anos, do sexo masculino e do sexo feminino, da rede de educação pública da cidade de João Pessoa. Essa amostra foi do tipo intencional, pois, além do propósito de garantir a validade externa de alguns instrumentos da pesquisa, era assegurada a possibilidade de realizar as análises estatísticas que permitissem estabelecer as associações entre as variáveis avaliadas.

\section{Instrumentos}

\section{Os participantes responderam os seguintes questionários}

Atributos de Individualismo e Coletivismo. Composto por seis itens que avaliam os atributos que mais caracterizam os sujeitos em relação ao individualismo e coletivismo (por exemplo, Cooperador, que colabora; Um ser único, diferente dos demais; Orientado ao êxito, ao triunfo, etc.). Adaptado por Formiga e Mota (2009) e que apresentou, a partir de uma análise fatorial confirmatória (AFC) e a análise do modelo de equação estrutural (SEM), indicadores de ajustes recomendados na literatura vigente (Byrne, 1989; Hair, Tatham, Anderson \& Black, 2005; van de Vijver \& Leung, 1997): $\chi^{2} /$ $\mathrm{gl}=3,01 ; \mathrm{GFI}=0,99$ e AGFI $=0,97 ; \mathrm{TLI}=0,93$; RMSEA $(90 \%$ IC $)=0,05(0,03-0,08)$, CAIC $=131,58$ e ECVI $=$ 0,07 . 0 instrumento proposto apresentou garantia de maior confiabilidade fatorial e evidências empíricas para sua aplicação e mensuração no contexto paraibano. Para respondê-lo, o jovem deveria ler cada item e indicar o quanto cada um dos atributos lhe caracteriza; para isso, era necessário apontar (com um X ou círculo) numa escala do tipo Likert, com os seguintes extremos: $\mathbf{0}=$ Nada Característico e $\mathbf{5}=$ Muito Característico, ao lado dos respectivos atributos.

Escala de Condutas Antissociais e Delitivas. Este instrumento, proposto por Seisdedos (1988) e validado por Formiga e Gouveia (2003) para o contexto brasileiro, compreende em uma medida comportamental em relação às Condutas Antissociais $e$ Delitivas. Tal medida é composta por 40 elementos, distribuídos em dois fatores, como segue: condutas antissociais. Seus elementos não expressam delitos, mas comportamentos que desafiam a ordem social e infligem normas sociais (por exemplo, jogar lixo no chão mesmo quando há perto um cesto de lixo; tocar a campainha na casa de alguém e sair correndo); e condutas delitivas. Estas incorporam comportamentos delitivos que estão fora da lei, caracterizando uma infração ou uma conduta faltosa e prejudicial a alguém ou mesmo a sociedade como um todo (por exemplo, roubar objetos dos carros; conseguir dinheiro ameaçando pessoas mais fracas). Para cada elemento, os participantes deveriam indicar o quanto apresentava o comportamento assinalado no seu dia a dia. Para isso, utilizavam uma escala de resposta com dez pontos, tendo os seguintes extremos: $\mathbf{0}=$ Nunca e $\mathbf{9}=$ Sempre.

A presente escala revelou indicadores psicométricos consistentes identificando os fatores destacados anteriormente; para a Conduta Antissocial foi encontrado um Alpha de Cronbach de 0,86 e a Conduta Delitiva ou Delinquente, 0,92. Considerando a Análise Fatorial Confirmatória, realizada com o Lisrel 8.0, comprovou-se essas dimensões previamente encontradas 
$\left(\chi^{2} / \mathrm{gl}=1,35 ;\right.$ AGFI $=0,89 ;$ PHI $\left.(\phi)=0,79, \mathrm{p}>0,05\right)$ na análise dos principais componentes (Formiga, 2003; Formiga \& Gouveia, 2003).

Caracterização Sociodemográfica. Os participantes responderam um conjunto de perguntas sobre característica pessoais (sexo, idade etc.) com a finalidade de caracterizar os respondentes da pesquisa.

\section{Procedimento e análise dos dados}

Para a aplicação do instrumento, o responsável pela coleta dos dados visitou a coordenação ou diretoria das instituições de ensino, falando diretamente com os diretores e/ou coordenadores para depois tentar a permissão junto aos professores responsáveis de cada disciplina, procurando obter sua autorização para ocupar uma aula e aplicar os questionários. Sendo autorizado, os estudantes foram contatados, expondo sumariamente os objetivos da pesquisa, solicitando sua participação voluntária. Para isso, foi-lhes dito que não havia resposta certa ou errada e que mesmo necessitando uma resposta individual, estes não deveriam se ver obrigados em respondê-los podendo desistir a qualquer momento seja quanto tivesse o instrumento em suas mãos ou ao iniciar sua leitura, ou outra eventual condição. Em qualquer um desses eventos, não haveria problema de sua desistência.

A todos era assegurado o anonimato das suas respostas, enfatizando que elas seriam tratadas em seu conjunto estatisticamente; apesar de o questionário ser autoaplicável, contando com as instruções necessárias para que pudessem ser respondidos, os colaboradores estiveram presentes durante toda a aplicação para retirar eventuais dúvidas ou realizar esclarecimentos que se fizessem indispensáveis, não interferindo na lógica e compreensão das respostas dos respondentes. Um único aplicador, previamente treinado, esteve presente em sala de aula, apresentando os instrumentos, solucionando eventuais dúvidas e conferindo a qualidade geral das respostas emitidas pelos respondentes.

No que se refere à análise dos dados desta pesquisa, utilizou-se a versão 18.0 do pacote estatístico SPSS para Windows. Foram computadas estatísticas descritivas (tendência central e dispersão). Indicadores estatísticos para o Modelo de Equações Estruturais (SEM) foram considerados segundo uma bondade de ajuste subjetiva, dada pelo $\chi^{2} / g l$ (grau de liberdade), que admite como adequados índices entre 2 e 3 , aceitando-se até 5; RMR, que indica o ajustamento do modelo teórico aos dados, na medida em que a diferença entre os dois se aproxima de zero. Para o modelo ser considerado bem ajustado, o valor deve ser menor que 0,05 ; índices de qualidade de ajuste, dados pelos $G F I / A G F I$, que medem a variabilidade explicada pelo modelo, e com índices aceitáveis a partir de 0,$80 ; N F I$, varia de zero a um e pode ser considerado aceitável para valores superiores a 0,90 . Caracteriza-se por ser uma medida de comparação entre o modelo proposto e o modelo nulo, representando um ajuste incremental; $C F I$, que compara de forma geral o modelo estimado e o modelo nulo, considerando valores mais próximos de um como indicadores de ajustamento satisfatório e a RMSEA, refere-se a erro médio aproximado da raiz quadrática, deve apresentar intervalo de confiança como ideal situado entre 0,05 e 0,08 (Byrne, 2001; Hair, Tatham, Anderson \& Black, 2005; Joreskög \& Sörbom, 1989).

\section{Resultados e discussão}

Com a finalidade de atender o objetivo do presente estudo - testar o modelo teórico (causal) para explicar as condutas desviantes a partir da orientação cultural de individualismo e coletivismo em diferentes escolas - considerou-se um modelo recursivo de equações estruturais. Visando a uma melhor compreensão dos resultados, avaliou-se a consistência do modelo, especificado para cada escola.

\section{Modelo teórico para a escola privada}

No que se refere à escola privada, observando a Figura 1, após as devidas modificações de ajuste, encontrou-se um modelo adequado que corrobora a hipótese levantada apresentando a seguinte razão $\chi^{2} / \mathrm{gl}=1,04 ; \mathrm{RMR}=0,01 ; \mathrm{GFI}=0,99 ; \mathrm{AGFI}=0,98 ;$ $\mathrm{CFI}=1,00, \mathrm{NFI}=0,99$ e RMSEA $=0,01(0,00-0,14)$. Os pesos (saturações) que explicam o modelo da variável considerada no tipo de orientação cultural coletivista (Cooperador, que colabora; Cumpridor com os demais, servidor) associou-se $(\lambda=-0,28)$, negativamente, às condutas antissociais, esta por sua vez, intermediou, positivamente $(\lambda=0,64)$, à conduta delitiva. Todas as saturações (Lambdas, $\lambda$ ) estão dentro do intervalo esperado $\mid 0$ - 1|, denotando não haver problemas de estimação proposta, pois todas estiveram estatisticamente diferentes de zero $(t>1,96, p<0,05)$. 


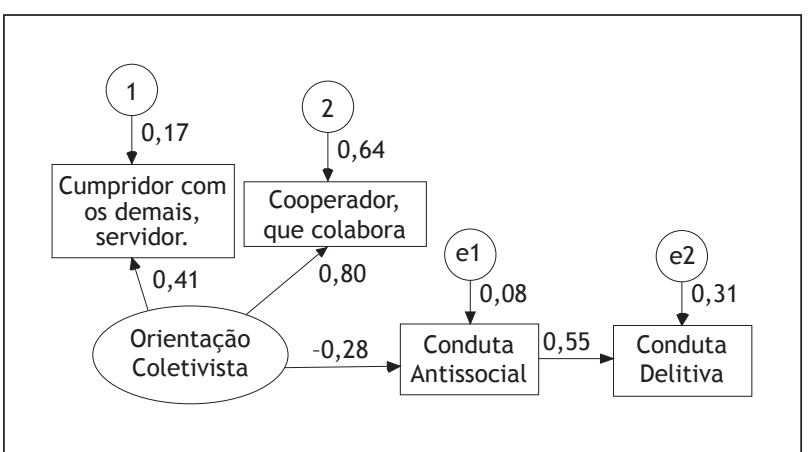

Figura 1 - Modelagem estrutural para explicação da conduta desviante (antissocial e delitiva) a partir do tipo de orientação cultural coletivista para a escola privada

Fonte: Dados da pesquisa.

Ainda considerando a amostra da escola privada, elaborou-se a hipótese com a orientação cultural individualista, a qual espera que ela se associe, positivamente, com a conduta antissocial, sendo essa, mediadora da conduta delitiva. Na Figura 2, realizadas as devidas modificações, encontrou-se o modelo esperado para essa hipótese, tendo a seguinte razão: $\chi^{2} / \mathrm{gl}=0,02 ; \mathrm{RMR}=0,002 ; \mathrm{GFI}=0,99 ; \mathrm{AGFI}=0,99 ;$ $\mathrm{CFI}=1,00, \mathrm{NFI}=0,99$ e RMSEA $=0,00(0,00-0,02)$. Os pesos que explicam o modelo da variável tipo de orientação cultural individualista (Um ser único, diferente aos demais; Orientado ao êxito, ao triunfo), associou-se $(\lambda=-0,28)$, positivamente, às condutas antissociais, e se associou, também, com um lambda positivo $(\lambda=0,55)$, à conduta delitiva. Todas as saturações (Lambdas, $\lambda$ ) estão dentro do intervalo esperado $\mid 0$ - 1|, denotando não haver problemas de estimação proposta, pois todas estiveram estatisticamente diferentes de zero $(t>1,96, p<0,05)$.

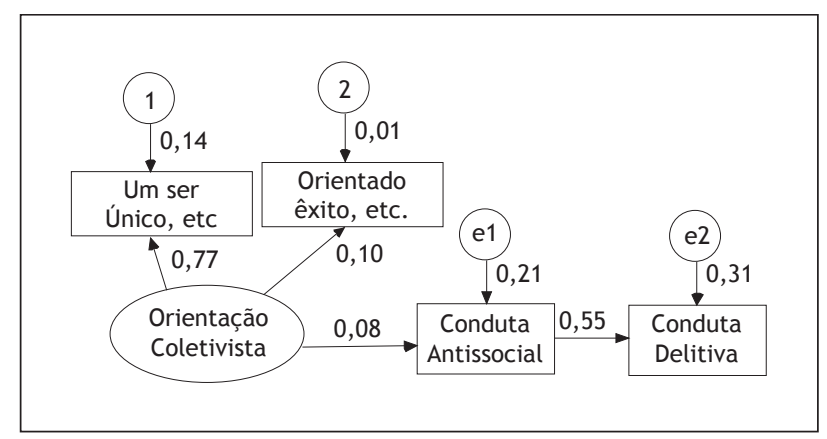

Figura 2 - Modelagem estrutural para explicação da conduta desviante (antissocial e delitiva) a partir do tipo de orientação cultural individualista para a escola privada

Fonte: Dados da pesquisa.

\section{Modelo teórico para a escola pública}

Realizou-se o mesmo procedimento estatístico com a amostra da escola pública; considerou-se que a orientação cultural coletivista se associaria, negativamente, com a conduta desviante (antissocial e delitiva). Na Figura 3, encontrou-se um modelo que prova tal hipótese; com as devidas modificações de ajuste observou-se a seguinte razão: $\chi^{2} /$ $\mathrm{gl}=0,97 ; \mathrm{RMR}=0,01 ; \mathrm{GFI}=1,00 ; \mathrm{AGFI}=0,99 ; \mathrm{CFI}$ $=1,00, \mathrm{NFI}=0,99$ e RMSEA $=0,01(0,00-0,10)$. Os pesos (saturações) que explicam o modelo da variável considerada no tipo de orientação cultural coletivista (Cooperador, que colabora; Cumpridor com os demais, servidor) associou-se, negativamente, às condutas antissociais. Estas, por sua vez, intermediaram a conduta delitiva.

Todas as saturações (Lambdas, $\lambda$ ) estão dentro do intervalo esperado $|0-1|$, denotando não haver problemas de estimação proposta. Além disso, todas são estatisticamente diferentes de zero $(t>1,96, p<$ $0,05)$; a orientação coletivista apresentou lambda negativo $(\lambda=-0,30)$ em relação à conduta antissocial, que por sua vez, media a conduta delitiva $(\lambda=0,64)$.

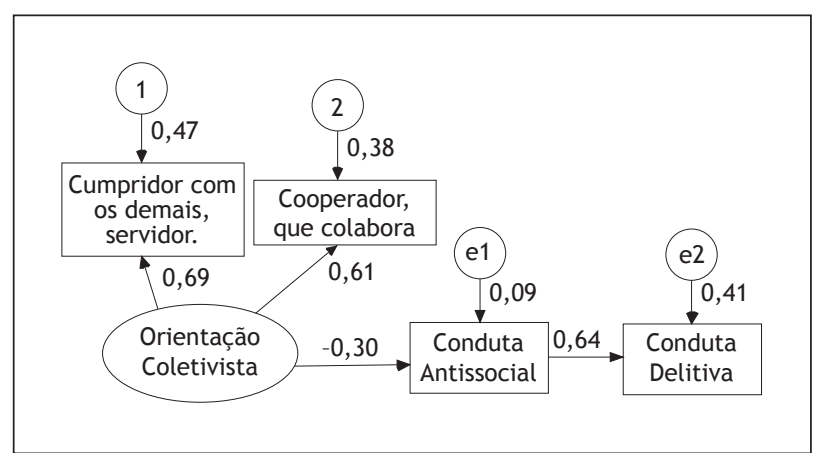

Figura 3 - Modelagem estrutural para explicação da conduta desviante (antissocial e delitiva) a partir do tipo de orientação cultural coletivista para a escola publica

Fonte: Dados da pesquisa.

Considerando a orientação cultural individualista, para amostra da escola pública, observou-se uma associação positiva com a conduta desviante (antissocial e delitiva), de acordo com o que se esperava. $\mathrm{Na}$ Figura 4, pode-se observar um modelo que corrobora a hipótese; feitas as devidas modificações de ajuste encontrou-se a seguinte razão: $\chi^{2} / \mathrm{gl}=1,08$; $\mathrm{RMR}=$ 0,$01 ; \mathrm{GFI}=0,99 ; \mathrm{AGFI}=0,98 ; \mathrm{CFI}=0,99, \mathrm{NFI}=1,00$ e RMSEA $=0,01(0,00-0,09)$. Os pesos que explicam 
que o modelo do tipo de orientação cultural individualista associou-se, positivamente $(=0,15)$ às condutas antissociais; estas se associaram $(\lambda=0,64)$ à conduta delitiva. Todas as saturações (Lambdas, $\lambda$ ) estão dentro do intervalo esperado $\mid 0$ - $1 \mid$ e são estatisticamente diferentes de zero $(t>1,96, p<0,05)$, indicando a não existência de problemas de estimação proposta.

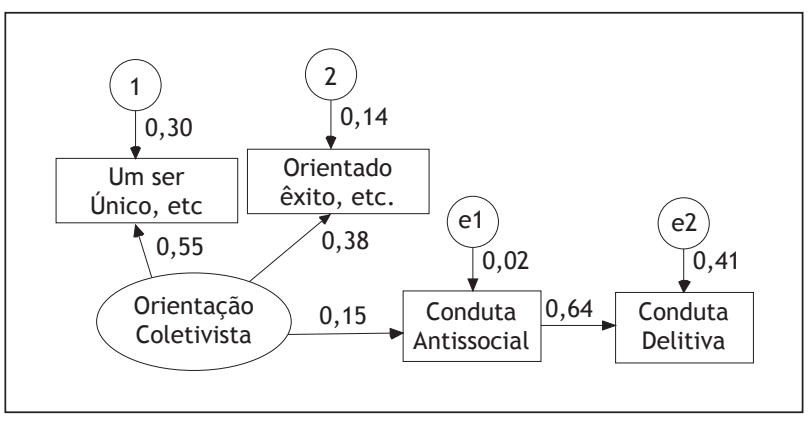

Figura 4 - Modelagem estrutural para explicação da conduta desviante (antissocial e delitiva) a partir do tipo de orientação cultural individualista para a escola pública

Fonte: Dados da pesquisa.

Os resultados do presente estudo, além de corroborar com uma maior consistência e robustez o modelo proposto, em relação aos achados de Formiga e Mota (2009) e de Formiga e Diniz (2011), pode-se refletir que um sujeito, ao apresentar atributos individualistas - por exemplo, Um ser único, diferente dos demais; Orientado ao êxito - provavelmente, apresentará condutas desviantes; o sujeito individualista é capaz de expressar uma tendência ao sucesso, a valorizar a própria intimidade e uma necessidade de adequar-se ao contexto social apenas para obter recompensas exclusivamente pessoais. Quando conseguem realizar isto, de acordo com Formiga e Diniz (2011), tendem a quebrar as normas sociais a fim de que as coisas sejam do jeito que eles querem, não considerando o grupo ou os pares responsáveis pelo controle social (por exemplo, pais, professores, etc.).

Em direção inversa, um sujeito com atributos coletivistas teria menor conduta desviante; o jovem com esses atributos - por exemplo, Cumpridor com os deveres, servidor; Cooperador, que colabora tende a ser cooperativo e busca respeitar a lei e as normas sociais, mantendo uma relação entre si e seu entorno social, compartilhando os mesmos interesses, inibindo as condutas desviantes.
Quanto ao que se esperava que os resultados seriam semelhantes tanto para escola pública quanto privada, o modelo teórico pode ser considerado adequado e consistente; apesar disto, é destaque, ao se observar as figuras, especificamente, a Figura 2, que os escores associativos - isto é, os lambdas - entre as variáveis da orientação cultural - principalmente, a orientação individualista - apresentou um lambda baixo $(\lambda=0,08)$ em comparação com o resultado da escola pública (ver tabela 4). Isso não significa falha no modelo hipotetizado para a amostra da escola privada, mas merece maior cuidado quando se considerar que esses jovens são individualistas tanto quanto os jovens da escola pública. É possível que tais jovens apresentem menor escore associativo entre as variáveis graças às características do contexto escolar vivido nesse tipo de instituição.

\section{Conclusão}

Atualmente, uma valorização ao individualismo justificado sob a égide de liberdade e democracia tem sido experienciado por muitos jovens, sugerindo a quebra das regras sociais e o desrespeito aos direitos alheios e falta de um imperativo do dever, levando os jovens a investirem nas condutas de risco. Considerando os resultados observados nesse estudo, bem como a base teórica abordada e os acontecimentos cotidianos entre os jovens em relação à conduta desviante, parece evidente que esta é um reflexo cultural da dissolução dos limites e adesão às convenções institucionais e sociais para uma harmonia da sociedade e seu entorno humano.

Tal reflexão assemelha-se à perspectiva contemplada por Triandis $(1995,1996)$ no que se refere à orientação cultural um compartilhamento de atitudes, crenças, normas, papéis sociais e definições do eu, capaz de orientar as pessoas por um ou outro tipo de orientação cultural, a qual a partir de cada orientação - coletivista ou individualista - o sujeito juvenil poderá se comportar de forma variada culturalmente, para si ou para o outro. As pessoas são um pouco de cada uma dessas orientações, sendo o contexto ou a situação imediata, capaz de definir o estilo mais apropriado de comportamento - o tipo de orientação (Sinhá \&Triandis, 1994; Triandis, 1995; Triandis, Chen \& Chan, 1998) e influenciar maior ou menor conduta desviante.

Desta forma, a fim de inibir esse tipo de conduta seja antissocial ou delitiva - seria de grande utilidade 
estimular um traço de conduta que oriente o sujeito ao coletivismo, condição que, segundo Triandis (1995), é um atributo característico dos brasileiros; a afirmação desse autor aponta em direção de uma configuração psicossocial diante desta orientação social: as pessoas que se identificam com os grupos tradicionais na sociedade são também menos propensas a apresentar indícios de condutas antissociais e condutas delitivas (Formiga \& Diniz, 2011).

\section{Referências}

Barzun, J. (2002). Da alvorada à decadência: A história da cultura ocidental de $\mathbf{1 5 0 0}$ aos nossos dias. Rio de Janeiro: Campus.

Byrne, B. M. (1989). A primer of LISREL: Basic applications and programming for confirmatory factor analytic models. New York: Springer-Verlag.

Donohew, R. L., Hoyle, R. H., Clayton, R. R., Skinner, W. F., Colon, S. E., \& Rice, R. E. (1999). Sensation seeking and drug use by adolescents and their friends: Models for marijuana and alcohol. Journal Study of Alcohol, 60(5), 622-631.

Dumont, L. (1985). 0 individualismo: Uma perspectiva antropológica da ideologia moderna. Rio de Janeiro: Rocco.

Elias, N. (1994). 0 processo civilizador: Formação do estado e civilização. Rio de Janeiro: J. Zahar. Vol. 2

Farias, S. A., \& Santos, R. C. (2000). Modelagem de equações estruturais e satisfação do consumidor: Uma investigação teórica e prática. Revista de Administração Contemporânea, 4(3), 107-132.

Fernández-Armesto, F. (1999). Milênio: Uma história de nossos últimos mil anos. Rio de Janeiro: Record.

Formiga, N. S., \& Diniz, A. (2011 no prelo). Estilo da orientação cultural e condutas desviantes: Testagem de um modelo teórico. Revista Pesquisa em Psicologia, $\mathbf{5}(1)$.

Formiga, N. S., \& Gouveia, V. V. (2003). Adaptação e validação da escala de condutas antissociais e delitivas ao contexto brasileiro. Revista Psico, 34(2), 367-388.
Formiga, N. S., \& Mota, H. M. (2009). Estilo da orientação cultural e condutas desviantes: Um estudo correlacional em jovens paraibanos. Cadernos de Pesquisa Interdisciplinar em Ciências Humanas, 10(97), 158-180.

Formiga, N. S. (2002). Condutas antissociais e delitivas: Uma explicação em termos dos valores humanos. Dissertação de Mestrado. Universidade Federal da Paraíba, João Pessoa, PB.

Formiga, N. S. (2003). Fidedignidade da escala de condutas antissociais e delitivas ao contexto brasileiro. Psicologia Estudo, 8(2), 133-138.

Formiga, N. S. (2004). 0 tipo de orientação cultural e sua influência sobre os indicadores do rendimento escolar. Psicologia: Teoria e Prática, 16(1), 13-29.

Formiga, N. S. (2005a). Comprovando a hipótese do compromisso convencional: Influência dos pares socionormativos sobre as condutas desviantes em jovens. Psicologia: Ciência e Profissão, 25(4), 602-613.

Formiga, N. S. (2005b). Condutas antissociais e delitivas e relações familiares em duas áreas urbanas na cidade de Palmas-TO. Revista Aletheia, 22, 63-70.

Formiga, N. S., \& Gouveia, V. V. (2005). Valores humanos e condutas antissociais e delitivas. Psicologia: Teoria e Prática, 7(2), 134-170.

Formiga, N. S., Yepes, C., \& Alves, I. (2005). Descritores da orientação cultural e condutas juvenis: Correlatos dos atributos do individualismo e coletivismo e condutas anti-sociais e delitivas em jovens brasileiros In: Anais do IV Congresso Científico e V Jornada de Iniciação Científica CEULP-ULBRA. Palmas - TO: CEULP-ULBRA.

Gouveia, V. V., Clemente, M., \& Vidal, M. A. (1998). España desde dentro: El individualismo y el colectivismo como rasgos diferenciadores de las comunidades autónomas. Sociedade y Utopia, 11, 168-179.

Gullone, E., \& Moore, S. (2000). Adolescent risk-taking and the five-factor model of personality. Journal of Adolescent, 23(4):393-340.

Hair, J. F., Tatham, R. L., Anderson, R. E., \& Black, W. (2005). Análise multivariada de dados. Porto Alegre: Bookman. 
Hofstede, G. (1980). Culture's consequences. Beverly Hills: Sage.

Inglehart, R. (1991). El cambio cultural en las sociedades industriales avanzadas. Madrid: Centro de Investigaciones Sociológicas; Siglo XXI.

Joreskög, K., \& Sörbom, D. (1989). LISREL 7 user's reference guide. Mooresville: Scientific Software.

Lipovetsky, G. (1986). La era del vacío: Ensayos sobre el individualismo contemporáneo. Barcelona: Anagrama.

Rokeach, M. (1973). The nature of human values. New York: The Free Press.

Rokeach, M. (1979). Introduction. In M. Rokeach (Ed.). Understanding human values: Individual and societal (pp. 1-11). New York: The Free Press.

Romero, E., Sobral, J., Luengo, M. A., \& Marzoa, J. A. (2001). Values and antisocial behavior among Spanish adolescents. The Journal of Genetic Psychology, 162(1), 20-40.

Schwartz, S. H. (1990). Individualism-collectivism: Critique and proposed refinements. Journal of Cross-Cultural Psychology, 21(2), 139-157.

Seisdedos, N. C. (1988). Cuestionario A - D de conductas antisociais - delictivas. Madri: TEA
Sinha, D., \& Tripathi, R. C. (1994). Individualism in a collectivist culture: A case of coexistence of opposites. In U. Kim, H. C. Triandis, Ç. Kagitçibasi, S.-C. Choi \& G. Yoon (Ed.). Individualism and collectivism: Theory, method, and applications (pp. 123-136). Thousand Oaks: Sage.

Triandis, H. C. (1995). Individualism and collectivism Boulder: Westview Press.

Triandis, H. C. (1996). The psychological measurement of cultural syndromes. American Psychologist, 51(4), 407-415.

Triandis, H. C., Chen, X. P., \& Chan, D. K. S. (1998). Scenarios for the measurement of collectivism and individualism. Journal of Cross-Cultural Psychology, 29(2), 275-289.

Urra, J. (2003). Adolescencia y violencia, topicos y realidades. Revista Estudios de Juventud, 62(3), 11-44.

Van De Vijver, F., \& Leung, K. (1997). Methods and data analysis for cross-cultural research. Thousand Oaks: Sage.

Vermeiren, R., De Clippele, A., \& Deboutte, D. (2000). A descriptive survey of Flemish delinquent adolescents. Journal of Adolescence, 23(3), 277-285. 
